\title{
Superplastic Behavior of Al-Mg-Mn Alloy: An Experimental \& Numerical Investigation
}

\section{TAYYABA Zaman ${ }^{1 a}$, REHAN Qayyume ${ }^{1 \mathrm{~b},{ }^{*},}$, AMJAD Ali ${ }^{1}$, SHAHEED Khan ${ }^{1}$ and CHAOLI Maa ${ }^{2}$}

\author{
${ }^{1}$ Institute of Industrial Control System, Rawalpindi, Pakistan \\ ${ }^{2}$ School of Material Science and Engineering, Beihang University; Beijing 100191, China \\ aishmaelnn@gmail.com, b rehan1606@gmail.com, 'amjadalikhalil@gmail.com, \\ pe_shaheed@hotmail.com, ${ }^{\mathrm{e}}$ chaolimaa@buaa.edu.cn
}

\section{Keywords: Al-Mg-Mn Alloy, Hot Deformation, Re-crystallization, Cavitation, Microstructure}

\begin{abstract}
Deformation response of Al-4.46Mg-0.48Mn alloy under uniaxial tensile loading was investigated at temperatures ranging from $400-525^{\circ} \mathrm{C}$ and at strain rates of $3 \times 10^{-3} \mathrm{~s}^{-1}, 10^{-3} \mathrm{~s}^{-1}$ and $10^{-4} \mathrm{~s}^{-1}$. The alloy exhibited a maximum elongation $>480 \%$ at a strain rate of $10^{-3} \mathrm{~s}^{-1}$ and $525^{\circ} \mathrm{C}$. At all conditions, the dominant deformation mechanism governing the superplastic deformation was investigated as a function of strain rate and temperature. The contributions of strain-rate sensitivity and strain hardening were analyzed in relation to the observed tensile ductility. The strain rate sensitivity index (m) and average activation energy (Q) values revealed that the dominant deformation mechanism was grain boundary sliding (GBS). The GBS phenomenon was further confirmed through high magnification examination of deformed surface. Optical microscopy (OM) and Scanning Electron Microscopy (SEM) showed that dynamic re-crystallization occurs during hot deformation of the alloy which causes reasonable enhancement of plasticity.
\end{abstract}

\section{Introduction}

Superplastic response in metals is inherently linked with microstructural aspects such as grain size, grain size stability, and resistance to cavitation. Furthermore, it is believed that the dominant deformation mechanism is a function of the imposed strain rate, temperature, and microstructural characteristics [1-4]. To achieve superplasticity in alloys such as Al alloys, the sheet is specially processed to develop a fine and stable grain size. The materials, in which superplastic behavior is enhanced by alloying additions; or processed by special thermo-mechanical treatments in order to acquire their fine grain size, exhibit large tensile elongations $>1000 \%$. However low deformation rate $(\dot{\varepsilon})$ for materials under discussion results in long forming times associated with a strain rates, generally lower than $3 \times 10^{-3} \mathrm{~s}^{-1}[5]$. These fine grain material have limited applications in automotive and aerospace sectors, due to productivity requirements. Since rolled products are the best choice for industrial production, "engineering superplasticity" is mostly related with materials that do not fall strictly in definition of superplasticity and deformation of such products is characterized as "quasi-superplasticity" or "enhanced ductility" [6-7].

The strain-rate sensitivity index of a material ( $\mathrm{m}$ value) is an indicator of its superplastic potential. The attribute is also intrinsically connected with the microstructural characteristics [8]. As superplastic straining continues, the microstructures in these alloys tend to evolve, experiencing grain growth, nucleation and growth of cavities. These microstructural changes often result in a loss of superplastic response, leading to premature fracture. Superplastic forming of AA5083 alloy has been extensively studied in the literature, but a little attention has been given to superplastic deformation in commercial grade Al-Mg alloys. Present study emphasizes on the investigation of hot deformation behavior of commercial grade Al- $4.46 \mathrm{Mg}-0.48 \mathrm{Mn}$ alloy at strain rates of $3 \times 10^{-3} \mathrm{~s}^{-1}$, $10^{-3} \mathrm{~s}^{-1}$ and $10^{-4} \mathrm{~s}^{-1}$ and wide range of temperatures $\left(400-550{ }^{\circ} \mathrm{C}\right)$ to optimize the superplastic deformation parameters where maximum ductility in the alloy is achieved. Detailed investigation of deformation and failure mechanisms of the alloy at different conditions is also included in this study. 


\section{Experimental Material and Procedure}

Material used in this investigation was Al-4.46Mg-0.48Mn alloy. Material was cold-rolled to $1 \mathrm{~mm}$ thickness plate with H111 temper. Initial microstructure of the experimental material shows equiaxed grains with initial grain size of about $15 \mu \mathrm{m}$, Fig. 1, some pre-existing micro voids can also be seen in the microstructure.

Fig. 1. Initial microstructure of material used in this study (H111 temper).

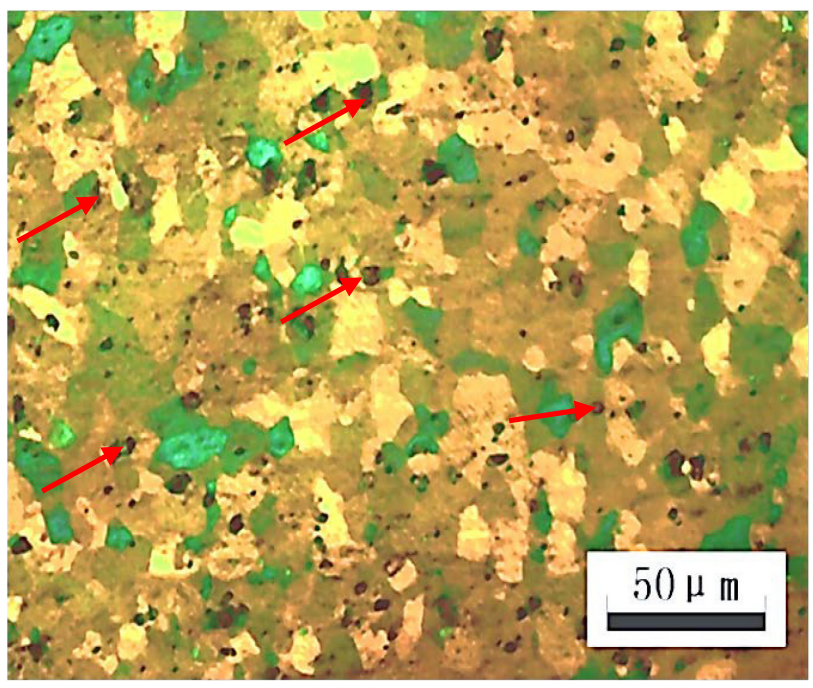

The sub sized "dog-bone" specimen geometries were used for uni-axial tensile testing of the alloy, with gauge length of $10 \mathrm{~mm}$ and gauge width of $6 \mathrm{~mm}$. The sheet rolling direction was oriented parallel to the tensile axis. Tensile tests were performed at temperatures ranging from $400^{\circ} \mathrm{C}-550^{\circ} \mathrm{C}$ and strain rates of $3 \times 10^{-3} \mathrm{~s}^{-1}, 10^{-3} \mathrm{~s}^{-1}$ and $10^{-4} \mathrm{~s}^{-1}$, in open atmosphere (air), using a screw-driven Hung Ta machine. Temperature was controlled within $\pm 1^{\circ} \mathrm{C}$ along each specimen gauge length using a resistance furnace with three independent heating zones. Load was measured using a $2000 \mathrm{KN}$ load cell and strain was calculated from cross-head displacement. Throughout each test the crosshead speed was kept constant. To investigate the microstructure evolution, tensile tests were interrupted and samples were water quenched at different strains. For optical microscopy (OM) samples were prepared by electrolytic anodizing in Barker's Reagent (1.87\% flouroboric acid and $98.2 \% \mathrm{H}_{2} \mathrm{O}$ ) with an applied voltage of 15 to $20 \mathrm{~V}$ (depending on sample condition) for 2 minutes.

Cavity nucleation during deformation, was analyzed using Energy Dispersive Spectroscopy (EDS). Samples deformed to different strain levels along with fractured surfaces were examined at high magnifications by SEM to characterize the deformation mechanism and investigate intrinsic micromechanisms governing fracture.

\section{Results and Discussions Mechanical Properties}

Elongation to Failure. Samples deformed to different strain levels are shown in Fig. 2. Elongation to failure achieved at $10^{-3} \mathrm{~s}^{-1}$ and different temperatures is shown in Fig. 3. A high level of elongation to failure $>480 \%$ was achieved at the strain rate of $10^{-3} \mathrm{~s}^{-1}$ and at temperature of $525{ }^{\circ} \mathrm{C}$, which is maximum for the commercial grade $\mathrm{Al}-4.46 \mathrm{Mg}-0.48 \mathrm{Mn}$ alloy being investigated. Elongation appears to be correlated with strain rate and temperature. Due do inter-linkage and coalescence of micro-voids, at a stage comes when cavity weakened material no longer support the flow stress. Ductility is significantly reduced at this stage (in this case at $550{ }^{\circ} \mathrm{C}$ ). 


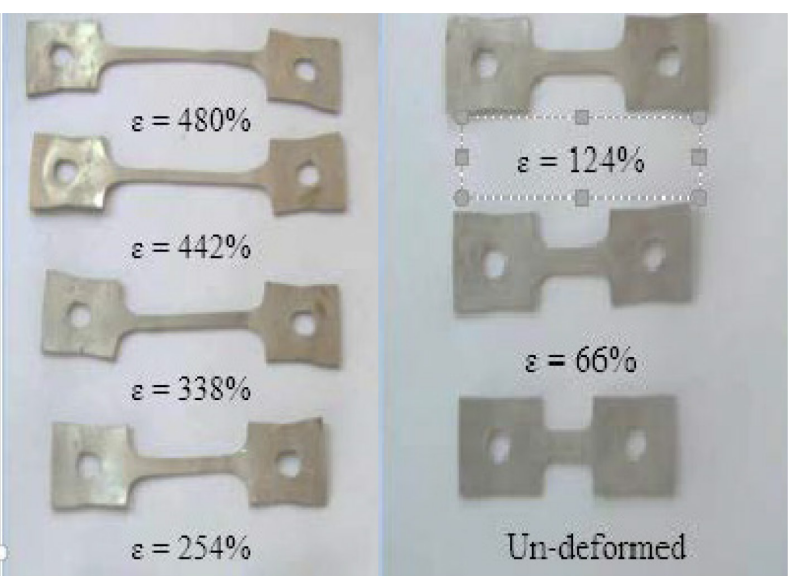

Fig. 2. Samples deformed to different strains at strain rate of $10^{-3} \mathrm{~s}^{-1}$

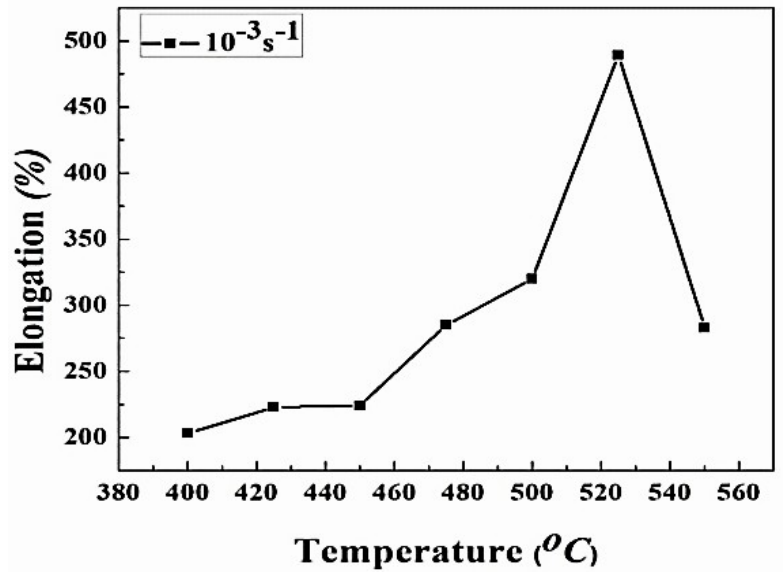

Fig. 3. Elongation to failure vs. Temperature at lower strain rate $\left(10^{-3} \mathrm{~s}^{-1}\right)$

True Stress vs. True Strain. Hot deformation properties, flow stresses and the shapes of the flow curves are dependent on test temperatures and the initial strain rates during constant cross head speed tests. Flow stress decreased with temperature, and increased with strain rate. True stress True strain curves for the investigated alloy at $400^{\circ} \mathrm{C}-550^{\circ} \mathrm{C}$ at initial strain rates of $3 \times 10^{-3} \mathrm{~s}^{-1}$, $10^{-3} \mathrm{~s}^{-1}$ and $10^{-4} \mathrm{~s}^{-1}$ are shown in Fig. 4. Stresses were lower than $60 \mathrm{MPa}$ for almost all the tested conditions. After a rapid increase of the stresses to approximately 5\% strain, tests performed show material hardening at lower initial strain rates. Reason for strain hardening in the alloy is dynamic grain growth and/or dislocation structure evolution [9-10]. Presumably the dominant deformation mechanism is grain boundary sliding, with associated grain growth [10]. Also lower deformation rates show a more sustained hardening rate which is maintained to higher strain levels (Fig. 4) due to dynamic grain growth. Extensive strain hardening takes place at the initial stage and after reaching a maximum value; flow stresses decrease continuously until fracture. Probable reason for the continuous decrease in flow stress till failure after attaining a maximum value is dynamic recrystallization occurring during hot deformation, where deformed grains are replaced by strain free grains.

Strain Rate Sensitivity (m) and Activation Energy (Q). The strain-rate sensitivity index $m$ is considered to be the most important parameter in characterization of superplastic deformation. The strain rate sensitivity index $\mathrm{m}$ and the activation energies of the two alloys were calculated according to the following constitutive equation [8]:

$$
\sigma=\mathrm{k}[\dot{\varepsilon} \exp (\mathrm{Q} /(\mathrm{RT}))]^{\mathrm{m}}
$$

Where $\sigma$ is the flow stress, $\mathrm{K}$ is a material constant, $\dot{\varepsilon}$ is the strain rate and $\mathrm{m}$ is the strain-rate sensitivity index of the flow stress, $\mathrm{Q}$ is the activation energy for superplastic deformation, $\mathrm{R}$ is the universal gas constant and $\mathrm{T}$ is absolute temperature. $\mathrm{Q}$ is a definite value at a certain temperature, so the strain rate sensitivity index $\mathrm{m}$ can be expressed by:

$$
\mathrm{m}=\delta \ln (\sigma) / \delta \ln (\varepsilon)
$$

The strain rate sensitivity index (m-value) is a function of forming parameters, such as strain rate and temperature. It is also linked with the microstructural characteristics. Strain rate sensitivity index " $\mathrm{m}$ " indicates capacity of a material to resist necking and has been used as a criterion to assess mechanisms of superplastic deformation. Large tensile elongations have been observed in metals exhibiting high $\mathrm{m}$ - value (typically $>0.3$ ). From low to high temperature, strain rate sensitivity index " $m$ " of the alloy is given in Fig. 5. These values are consistent with elongation to failure data. As plastic deformation by grain-boundary sliding is characterized by " $\mathrm{m}$ " value of the order of 0.5 [5], the calculated " $m$ " values predict that Grain Boundary Sliding (GBS) is dominant deformation mechanism governing hot deformation of the alloy. The activation energy ' $Q$ ' under constant strain rate can be calculated by the following equation deduced from Eq. 1 


$$
\mathrm{Q}=\frac{\mathrm{R} \partial \ln \sigma}{\mathrm{m} \partial(1 / \mathrm{T})}
$$

From the curves of $\ln \sigma$ versus $1 / \mathrm{T}, \partial \ln \sigma / \partial(1 / \mathrm{T})$ is estimated from the slopes of the fitted linear regression lines in Fig. 6. The average activation energy of the alloy at strain rate of $10^{-3} \mathrm{~s}^{-1}$ is found to be $86.5 \mathrm{~kJ} /$ mole. The activation energies for the Solute Drag (SD) and GBS creep mechanisms are $\mathrm{Q}_{\mathrm{SD}}-136 \mathrm{~kJ} / \mathrm{mole}$ and $\mathrm{Q}_{\mathrm{GBS}}-110 \mathrm{~kJ} / \mathrm{mole}$ [11]. The calculated activation energy is much less than reported value associated with deformation of Al-Mg alloys by SD creep (136k $\mathrm{J} / \mathrm{mole}$ ) [10]. Also, the calculated value is much less than the activation energies required for $\mathrm{Al}$ lattice self-diffusion (142 kJ/mole) and for magnesium diffusion in aluminum $(136 \mathrm{~kJ} / \mathrm{mole})[7,16]$. This lower activation energy for the alloy is likely to be attributed to an increased contribution of grain boundary diffusion in total plastic flow [7]. The activation energy for the alloy calculated at $10^{-3} \mathrm{~S}^{-1}$ is consistent with the low activation energies observed during deformation by GBS creep when grain-boundary diffusion participates actively.

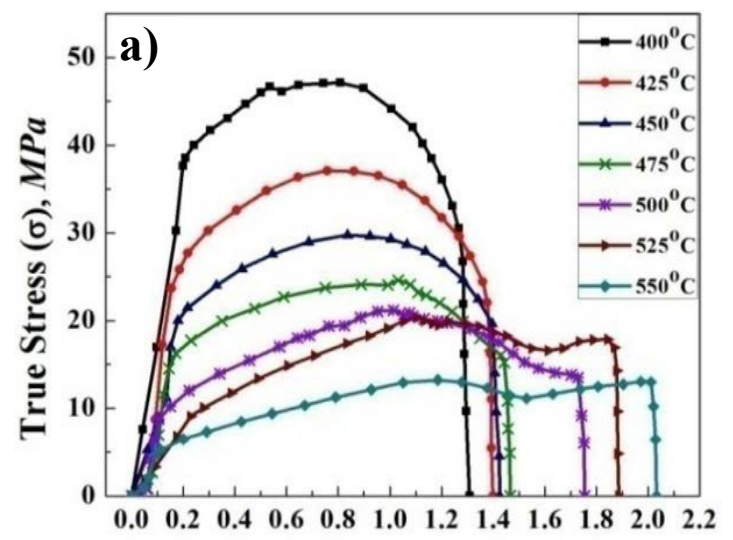

True Strain $(\varepsilon)$

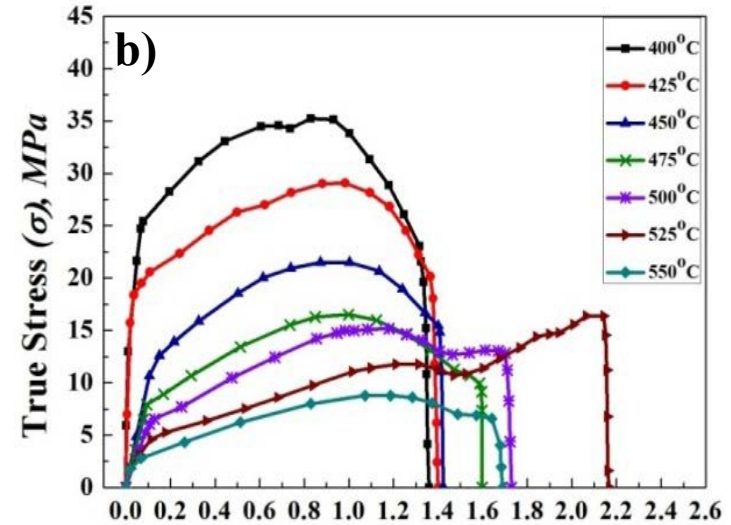

True Strain $(\varepsilon)$

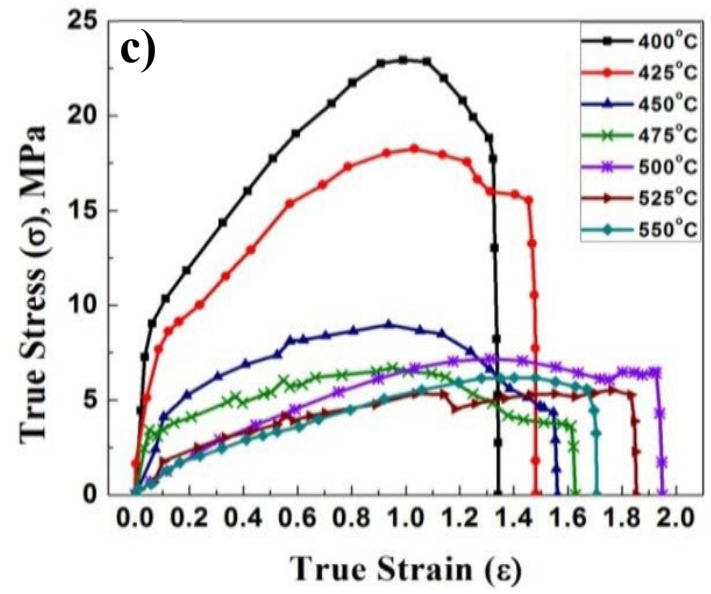

Fig. 4. True stresses vs true strains in temperature range of $400^{\circ} \mathrm{C}-550^{\circ} \mathrm{C}$ at;
(a) $3 \times 10^{-3} \mathrm{~s}^{-1}$;
;(b) $1 \times 10^{-3} \mathrm{~s}^{-1}$;
; (c) $1 \times 10^{-4} \mathrm{~s}^{-1}$ 


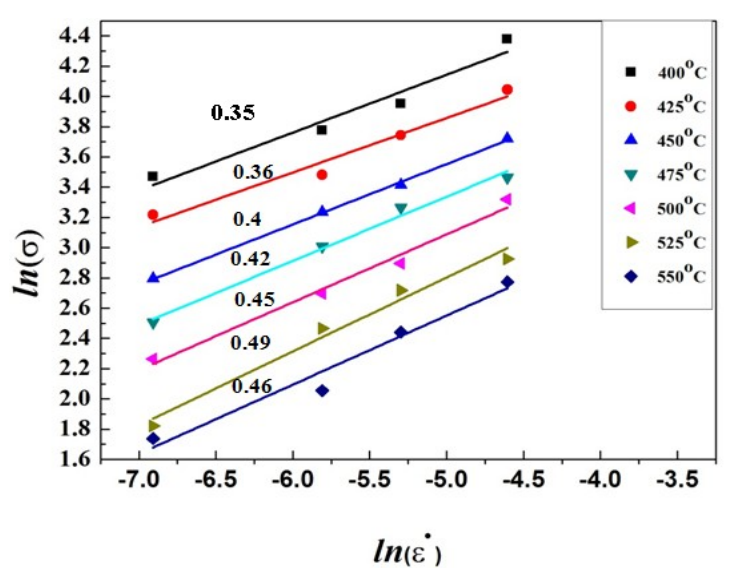

Fig. 5. Strain Rate Sensitivity co-efficient " $m$ " values, calculated from slopes of linear regression lines in the plot $(\ln \sigma$ vs $\ln \boldsymbol{\varepsilon})$, at various temperatures

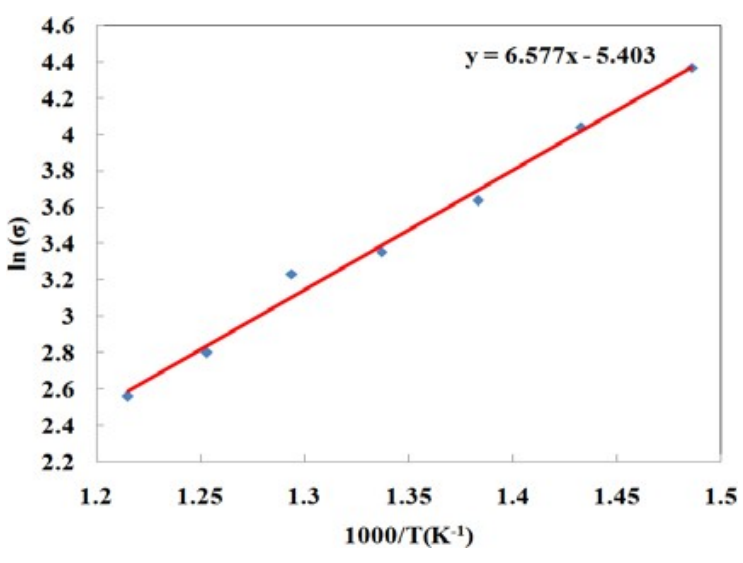

Fig. 6. Measured and linear fitted values between $\ln \sigma$ and $1 / \mathrm{T}$ at $10^{-3} \mathrm{~S}^{-1}$

The value is close to the activation energy of grain boundary diffusion in aluminum alloy, $84 \mathrm{~kJ} / \mathrm{mol}[8,12]$. This suggests that the dominant mechanism of superplastic deformation in this alloy is grain boundary sliding accommodated by grain boundary diffusion [13-15].

\section{Deformation Mechanism.}

Grain Boundary Sliding (GBS). Fig. 7 illustrates the surface morphology of the specimens strained to $480 \%$ at strain rate of $10^{-3} \mathrm{~s}^{-1}$ and temperature of $525^{\circ} \mathrm{C}$, grain boundary sliding can easily be seen from the large number of grain boundary steps and off sets as shown in Fig. 7. Fibers were observed between adjacent grains along tensile direction (Fig. 7- 8), at $10^{-3} \mathrm{~s}^{-1}$ and $525{ }^{\circ} \mathrm{C}$, having total elongation of $480 \%$. The fibers are formed at grain boundaries having elongated cavities. Fibers are reported to originate from grain separation [17]. It is related with grain boundary delamination or voiding which is observed at the free surface during straining, especially at boundaries, normal to the tensile axis. It appears that grain separation also contributed to the total strain in addition to GBS. These observations are also consistent with numerically calculated value of "m" and "Q".
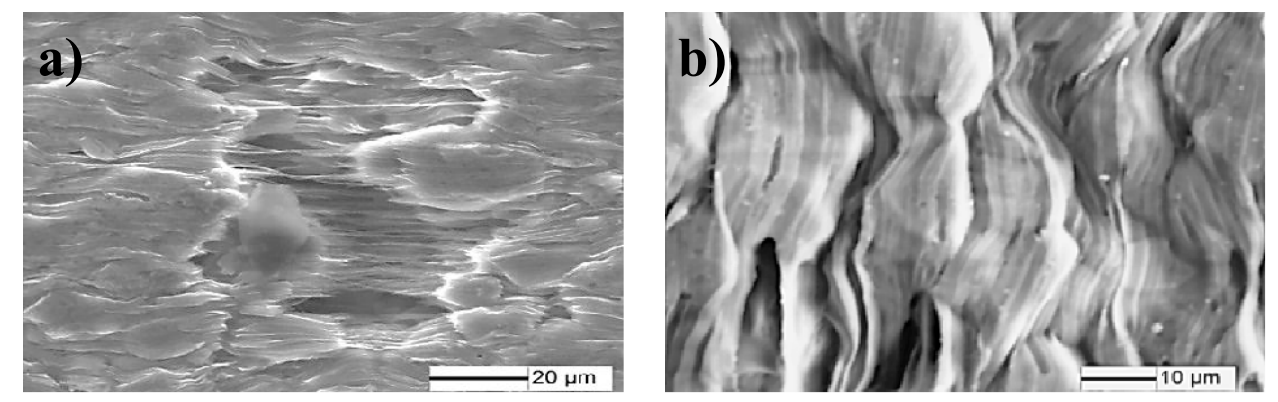

Fig. 7. Gauge section of samples deformed at a-b) $10^{-3} \mathrm{~s}^{-1}$ and $525^{\circ} \mathrm{C}(\delta=480 \%)$
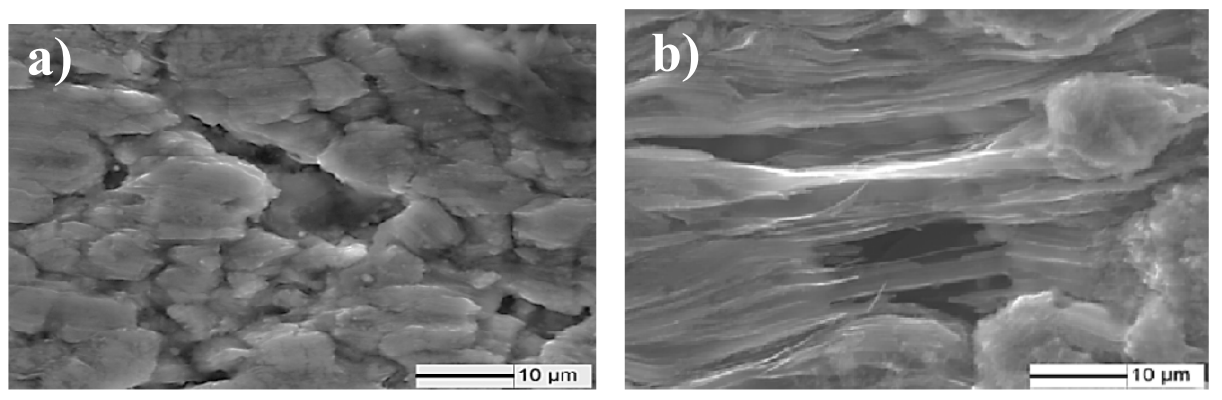

Fig. 8. Cavitation in samples deformed at a) $3 \times 10^{-3} \mathrm{~s}^{-1}$; b) $10^{-3} \mathrm{~s}^{-1}$ 

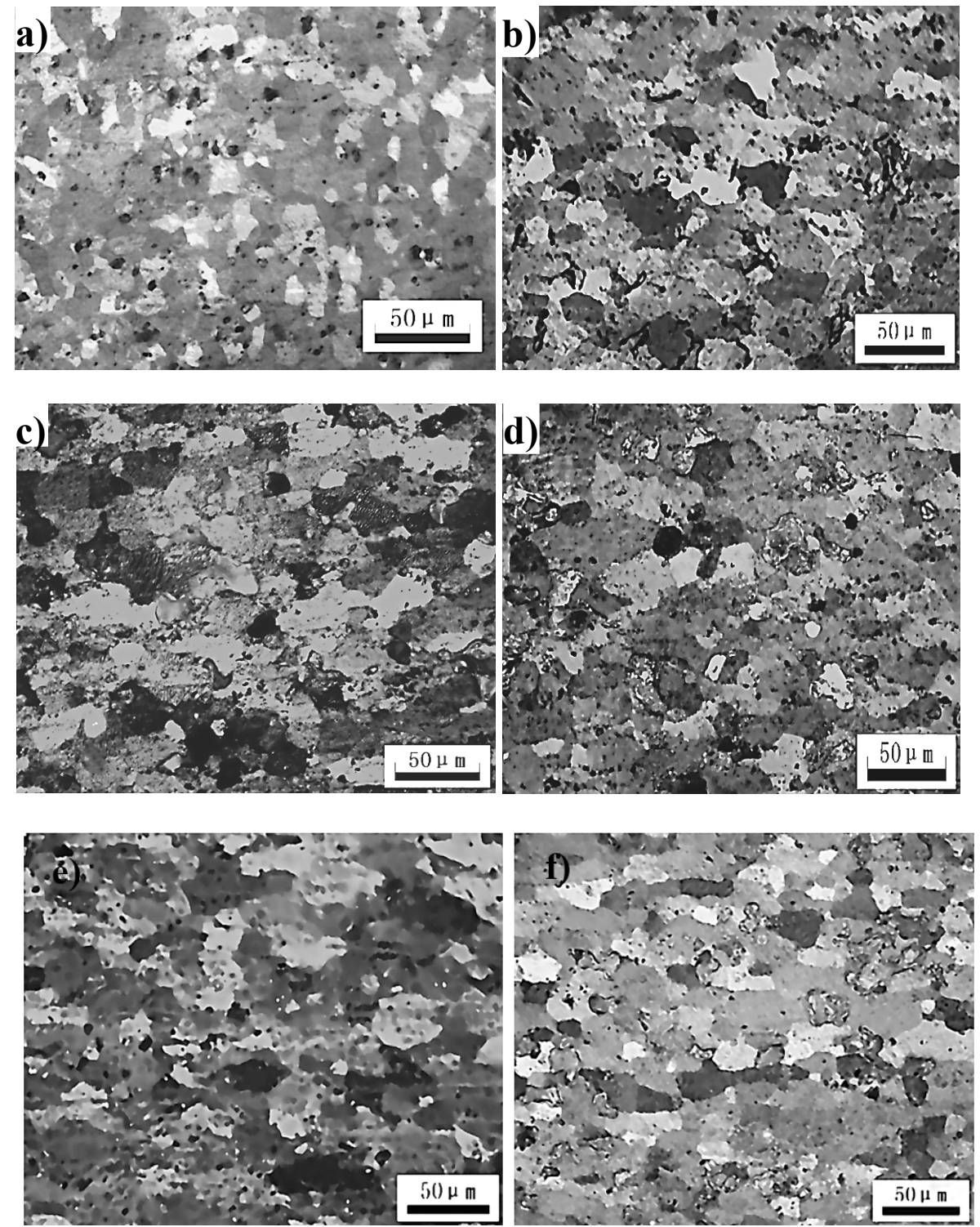

Fig. 9. a) Un-deformed; Deformed at $525 \mathrm{oC}$ and $10^{-3} \mathrm{~s}^{-1}$ to different strain levels of; b) $124 \%$; c) $254 \%$; d) $338 \%$; e) $442 \%$; f) $480 \%$
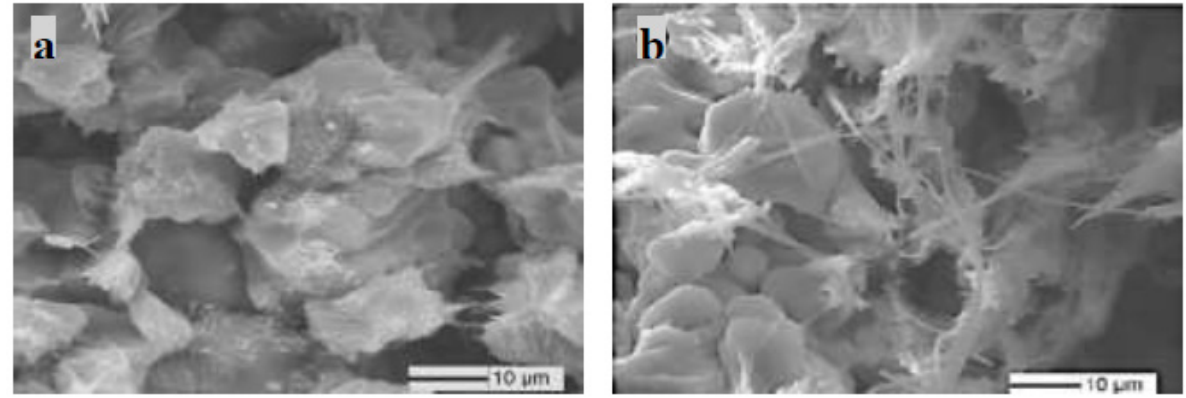

Fig. 10. Fracture surface of the failed specimens a), b) at $10^{-3} \mathrm{~s}^{-1}$ and $525^{\circ} \mathrm{C}$

Dynamic Grain Growth and Recrystallization. At high homologous temperatures $(>0.6 \mathrm{Tm})$ many metals and alloys exhibit dynamic recrystallization phenomenon. The tensile tests were interrupted at different strains and temperatures and the samples were water quenched to study the microstructure evolution. Samples deformed to different strain levels are shown in Fig. 9. Comparing microstructures of the samples deformed to different strain levels, dynamic grain growth is clearly evident. Large, highly strained and elongated grains are observed in samples strained from $124 \%$ to $480 \%$, it can also be observed that the microstructure contains a wide range of grain sizes. Also along with large and elongated grains, many equi-axed and new fine grains can 
also be seen clearly. This indicates that the alloy undergoes dynamic recrystallization during hot deformation. Fraction of new recrystallized grains increases with increasing strain (Fig. 9). Some strain free grains replace the deformed grains. High local dislocation densities at grain boundary heterogeneities such as triple points trigger dynamic recrystallization, as these are the preferred nucleation sites for recrystallized grains. Fig. 9 clearly shows emergence of recrystallized grains at grain boundary heterogeneities and variety of grain sizes, at high magnification. The stress-strain curves (Fig. 4) and microstructure analysis (Fig. 7-8) strongly indicate that dynamic recrystallization has a major role in superplastic behavior of the investigated alloy. After dynamic recrystallization, a more fine grained structure consisting of high-angle grain boundaries (HABs) is developed which promotes GBS. This explains the enhancement in plasticity of the alloy at strain rate of $10^{-3} \mathrm{~s}^{-1}$. As it is believed that random (disordered) HABs promotes the superplastic flow by GBS [17].

Fractured Surface. Fig. 10 a-b show the fracture surface of the samples deformed to $480 \%$ at $10^{-3} \mathrm{~s}^{-1}$ Fracture of the sample deformed to $480 \%$ at a slower initial rate of $10^{-3} \mathrm{~s}^{-1}$, is predominantly ductile consisting of large cavities, generated by micro-void inter-linkage and coalescence. Fractograph (Fig. 10) shows large cavities as a consequence of the coalescence of smaller voids. Also internal cavitation has a greater role in the failure mechanism, particularly at slower strain rates. Grain off-sets and grain separation due to GBS is clearly evident. Fibers can also be seen in Fig. 10b. Fibers are always formed due to grain separation and grain boundary delamination, at grain boundaries having elongated cavities, as discussed earlier.

\section{Conclusions}

1. Max elongation-to-failure value of $>480 \%$ was obtained at $525^{\circ} \mathrm{C}$ and strain rate of $10-3 \mathrm{~s}-1$.

2. Increasing temperature or decreasing strain rate leads to a reduction in flow stress.

3. Average activation energy $(\mathrm{Q})$ values predict that the dominant deformation mechanism is grain boundary sliding, which is supported by $m$ values and deformed surface observations.

4. Dynamic recrystallization occurs during hot deformation, develop a finer grained structure consisting of high-angle grain boundaries (HAGBs), at strain rate of 10-3 s-1, which promotes GBS.

\section{References}

[1]D.H. Avery and W.A. Backofen: A Structural Basis for Superplast., Trans., 58 (1965) 551-62.

[2]M.F. Ashby and R.A. Verrall: Diffusion-Accommodated Flow and Superplast. Acta Metal., 21 (1973) 149-63.

[3]R.C. Gifkins: Grain-Boundary Sliding and its Accommodation During Creep and Superplasticity, Metall. Trans., 7A (1976) 1225-1232.

[4]R.C. Gifkins: Effect of Grain Size and Stress Upon Grain Boundary Sliding, Metall. Trans., 10A (1977) 1507-16.

[5]T.G. Nieh, J. Wadsworth, O.D. Sherby, Superplasticity in Metals and Ceramics, Cambridge University Press, New York, 1996.

[6]E.M. Taleff, G.A. Henshall, T.G. Nieh, D.R. Lesuer, J. Wadsworth, Warm-temperature tensile ductility in Al-Mg alloys. Metall. Mat. Trans. A, 29 (1998) 1081-1092.

[7]S.S. Woo, Y.R. Kim, D.H. Shin, W.J. Kim, Effects of Mg concentration on the quasisuperplasticity of coarse-grained Al-Mg alloys. Scr. Mater., 37 (1997) 1351-1357.

[8]H. B. Genga, S. B. Kangb, B. K. Min, High temperature tensile behavior of ultra-fine grained A1-3.3Mg-0.2Sc- 0.2Zr alloy by equal channel angular pressing, J. Mat. Sci. Eng. A, A313 (2004) 229-238. 
[9]Kumar, D. Ravi, Swaminathan, K, Tensile deformation behaviour of two aluminum alloys at elevated temperatures, Mater. Hig. Temp., 16 (1999) 161- 172.

[10] G.Bernal, R.S. Mishra, et al., High strain rate superplasticity in continuous cast Al-Mg alloys prepared via friction stir processing, Scr. Mat., 60 (2009) 850-853.

[11] M.A. Kulas, W. Paul Green, et al., Deformation Mechanisms in Superplastic AA5083 . Metall. Mater. Trans.A, 36 (2005) 1249-1261.

[12] S. W. Lee, J. W. Yeh, Superplasticity of 5083 alloys with $\mathrm{Zr}$ and Mn additions produced by reciprocating extrusion, J. Mat. Sci. Eng. A, 460 (2007) 409-419.

[13] O. D. Sherby, J.Wadsworth, Super plasticity-recent advances and future directions, J. Prog. Mat. Sci., 33 (1989) 169-221.

[14] Watanabe H, MukaI T, Nieh T G, Higashi K. Low temperature superplasticity in a magnesiumbased composite [J]. Scripta Materialia, 2000, 42: 249-255.

[15] N. Q. Chinh, P. Szommera, T. Csanbi, T. G. Langdon, Flow processes at low temperatures in ultrafine-grained aluminum, J. Mat. Sci. Eng. A, 434 (2006) 326-334.

[16]H. Iwasaki, H. Hosokawa, T. Mori, T. Tagata, K. Higashi, Quantitative assessment of superplastic deformation behaviour in a commercial 5083 alloy, Mate. Sci. Eng. A, 252 (1998) 199-202.

[17] Y.N. Wang, J.C. Huang, Comparison of grain boundary sliding in fine-grained $\mathrm{Mg}$ and $\mathrm{Al}$ alloys during superplastic deformation, Scri. Mat., 48 (2003) 1117-1122. 